\title{
DETECÇÃO ELETROQUÍMICA EM ELETROFORESE CAPILAR
}

\author{
José Alberto Fracassi da Silva* \\ Escola Politécnica, Universidade de São Paulo, Av. Prof. Luciano Gualberto, Travessa 3, 158, 05508-900 São Paulo - SP
}

Recebido em 12/11/01; aceito em 11/6/02

\begin{abstract}
ELECTROCHEMICAL DETECTION IN CAPILLARY ELECTROPHORESIS. This review focuses the development of electrochemical detection systems coupled to capillary electrophoresis. Conductometric, amperometric, voltametric, and potentiometric modes of detection are reviewed. The positioning of the electrodes, interferences of high electric field, and the materials employed in the fabrication and modification of the electrodes are discussed. The advantages of the use of electrochemical detection with capillary electrophoresis, regarding to the sensitivity and selectivity, is exemplified with a large number of applications. Also, the use of electrochemical detection systems in microchip technology is addressed.
\end{abstract}

Keywords: capillary electrophoresis; electrochemistry; separation science.

\section{INTRODUÇÃO}

A eletroforese capilar (CE) é uma técnica de separação baseada nas diferenças de mobilidade dos analitos quando submetidos à ação de um campo elétrico. Hoje, a CE está bem estabelecida como técnica analítica e, devido aos mecanismos de separação completamente distintos da cromatografia líquida de alta eficiência, figura em muitos casos como técnica complementar a esta última. Detalhes sobre os mecanismos de separação e características da CE foram revisados em língua portuguesa por Tavares ${ }^{1,2}$. Resumidamente, a CE apresenta como características a alta eficiência de separação (tipicamente acima de $10^{5}$ pratos teóricos), baixo consumo de amostras (nL) e reagentes $(\mathrm{mL})$, tempos de análise reduzidos e alto grau de automação. A instrumentação básica conta, na sua modalidade mais simples (eletroforese de zona, ou CZE), com uma fonte de alta tensão onde o potencial é aplicado nas extremidades de um capilar através de eletrodos de platina mergulhados em reservatórios contendo tampão de corrida. O sistema de detecção é convenientemente posicionado no capilar. Normalmente, capilares de sílica fundida de 20 a $75 \mu \mathrm{m}$ (diâmetro interno) e recobertos externamente com uma camada de poliimida são empregados, embora também seja comum a utilização de capilares fabricados com material polimérico.

Devido à pequena quantidade de material introduzida no capilar, o desenvolvimento dos sistemas de detecção continua em destaque ainda hoje, após aproximadamente duas décadas desde sua introdução no formato atual ${ }^{3,4}$. De fato, artigos continuam sendo publicados abordando melhorias nos sistemas de detecção conhecidos e introduzindo novos conceitos. Os sistemas de detecção em CE seguem, $a$ priori, os mesmos esquemas utilizados em cromatografia líquida, sendo classificados em:

métodos ópticos - absorção de luz na região do ultravioleta-visível ou infravermelho, fluorescência, índice de refração, Raman, absorbância termo-óptica e quimiluminescência;

métodos eletroquímicos - amperométricos, voltamétricos, condutométricos e potenciométricos;

outros métodos e métodos acoplados - ressonância magnética nuclear, radiométricos, espectrometria de massas e de emissão com plasma indutivamente acoplado (ICP-AES).

*e-mail: fracassi@iq.usp.br
Este artigo enfoca o desenvolvimento dos métodos eletroquímicos de detecção aplicados à CE. Como primeira revisão em língua portuguesa que se tem conhecimento neste tipo de assunto, esta abrange o período desde o seu aparecimento em 1979, com o trabalho pioneiro de Everaerts e colaboradores ${ }^{3}$, até o ano de 2000, envolvendo periódicos indexados e de língua inglesa, abrangendo um total de 280 artigos consultados.

A detecção eletroquímica (ED) em CE tem sido tema de revisão nas duas últimas décadas ${ }^{5-25}$ (8\% dos artigos selecionados). É interessante notar que, apenas no ano de 2000, 6 artigos de revisão foram publicados, contra 4 em 1999 e apenas 2 em 1998. Se este fato isoladamente não pode ser utilizado como indicativo da crescente atividade nesta área, o gráfico na Figura 1 não deixa dúvidas a este respeito. Como indicado, o ano de 2000 engloba um total de 59 artigos, contra 34 em 1998, 27 em 1996 e apenas 14 em 1994.

Em relação às técnicas utilizadas, a maioria dos artigos selecionados na literatura (53\%) relaciona-se com detecção amperométrica (AD), seguidos da detecção condutométrica (CD, 22\%), potenciométrica ( $\mathrm{PD}, 7 \%$ ) e voltamétrica (VD, 4\%). Artigos envolvendo separações em micro-canais ( $\mu$ chip) e ED têm sido recentemente publicados, englobando $6 \%$ do total de artigos publicados.

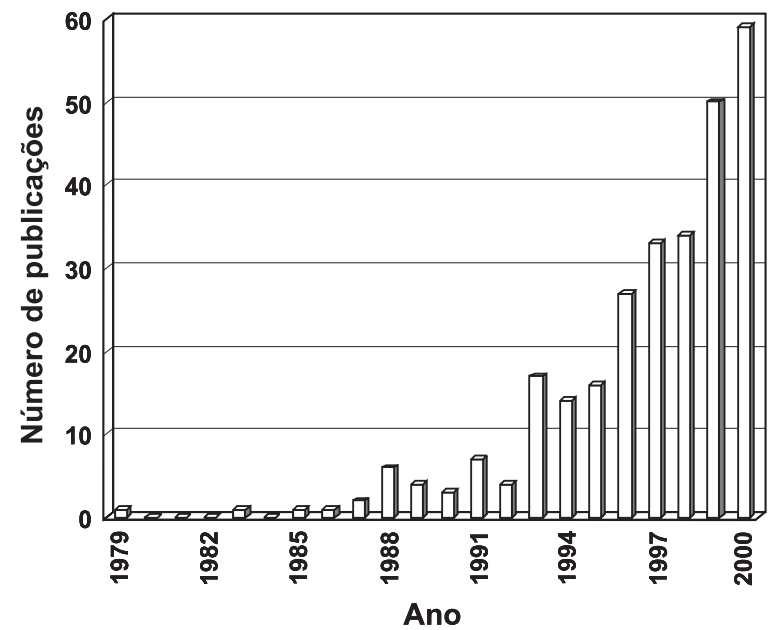

Figura 1. Evolução anual do número de publicações envolvendo detecção eletroquímica em eletroforese capilar 
Convém ressaltar que esta área está em franca expansão e espera-se, nos próximos anos, grande desenvolvimento no sentido da implementação de sistemas analíticos completos em $\mu$ chips na análise de rotina.

Espera-se, pois, com esta revisão, demonstrar a potencialidade e o estado da arte da ED aplicada à CE.

\section{POSICIONAMENTO DO ELETRODO DE TRABALHO E INTERFERÊNCIA DO CAMPO ELÉTRICO}

O posicionamento e alinhamento do eletrodo de trabalho no capilar merecem especial atenção, uma vez que estes parâmetros afetam a reprodutibilidade e a resposta dos sistemas de detecção eletroquímicos. $\mathrm{O}$ alto campo elétrico utilizado na separação possui significativa influência nos resultados, uma vez que interfere nas baixas correntes medidas (tipicamente na faixa de $10^{-9}$ a $10^{-12} \mathrm{~A}$ ). Como exemplo, um eletrodo de apenas $1 \mathrm{~mm}$, inserido no interior de um capilar ao qual é aplicado um campo de $200 \mathrm{~V} / \mathrm{cm}$, sofrerá uma queda de potencial de $20 \mathrm{~V}$, que é suficiente para que ocorram reações secundárias no eletrodo, com a prejudicial formação de bolhas. Praticamente, observa-se o aumento nos limites de detecção (LOD), devido ao aumento no ruído da linha base ${ }^{26}$.

Em relação ao posicionamento, os eletrodos de trabalho podem ser colocados ao longo do capilar (OnC, "on-column detection"), na sua extremidade (EndC, "end-column detection") ou mesmo utilizando-se uma coluna extra (OffC, "off-column detection”). Neste último caso, o capilar utilizado na separação é unido ao capilar de detecção através de um desacoplador. A Figura 2 ilustra as diferenças no posicionamento dos eletrodos de trabalho para estas configurações.

(1)

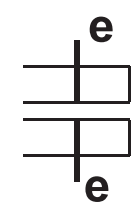

(2)

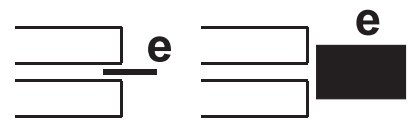

(3)

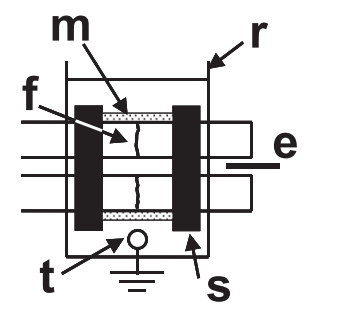

Figura 2. Posicionamento dos eletrodos no capilar: (1) "On-column”, (2) "End-column" (configuração "wall-jet" à direita) e (3) "Off-column". (e) Eletrodos de trabalho, (f) fratura no capilar, $(m)$ membrana permeável a ions, (r) reservatório com eletrólito, $(s)$ suporte para a membrana e $(t)$ eletrodo de platina ligado ao terra da fonte de alta tensão. Os eletrodos auxiliar e de referência não são mostrados

A detecção OnC é convenientemente empregada em métodos ópticos de detecção para CE, como absorção na região do ultravioletavisível e fluorescência, uma vez que, neste caso, o feixe de luz simplesmente atravessa uma região do capilar na qual o recobrimento de poliimida é retirado. $\mathrm{Na} \mathrm{ED}$, este esquema é utilizado em detectores condutométricos convencionais e aqueles que operam em alta freqüência e sem contato com a solução no interior do capilar.
Na detecção EndC o eletrodo é posicionado próximo da saída capilar. Alternativamente, o eletrodo de trabalho pode ser parcialmente inserido no orifício de saída. Neste caso, a corrosão da parede interna do capilar com HF proporciona aumento significativo na relação sinal-ruído, uma vez que o campo elétrico que recai sobre esta região é diminuído. Como os diâmetros internos dos capilares utilizados em CE são, normalmente, da ordem de dezenas de $\mu \mathrm{m}$, ocorre que em alguns casos os eletrodos de trabalho utilizados podem possuir diâmetro maior, tornando-se necessário o emprego da configuração "wall-jet" 27 . Um caso particular de detecção EndC é a deposição de filmes metálicos diretamente sobre o capilar, utilizando-se técnicas de "sputtering" ("on-capillary detection") ${ }^{28}$. Deste modo, o eletrodo de trabalho fica imobilizado no capilar, dispensando as etapas de alinhamento.

Alguns autores têm proposto celas eletroquímicas e arranjos que dispensam etapas laboriosas de alinhamento ${ }^{29-33}$.

A maneira mais eficiente de minimizar a interferência do campo elétrico utilizado na separação é através do emprego de desacopladores, como na detecção OffC. Neste tipo de configuração, promove-se um caminho alternativo à corrente elétrica utilizada na separação, sendo este do reservatório de injeção até um reservatório auxiliar, passando através do desacoplador. Devido à existência do fluxo eletroosmótico (EOF), o analito de interesse é movido para o capilar de detecção, ao final do qual o eletrodo de trabalho é posicionado.

\section{DESACOPLAMENTO}

A fabricação dos desacopladores utilizados em CE é realizada a partir da fratura do capilar de sílica na região próxima à sua extremidade. A seguir, esta região é imobilizada, de maneira a aumentar a resistência mecânica do dispositivo. Uma membrana porosa é posicionada ao longo da fratura para que haja condução de corrente, embora alguns autores tenham dispensado o uso da membrana, posicionando o eletrodo utilizado na separação (conectado à fonte de alta tensão) imediatamente após a fratura ${ }^{26,34-40}$. Finalmente, o conjunto é colocado em contato com o eletrodo de separação através de eletrólito apropriado.

Vários tipos de materiais, como vidro poroso ${ }^{41-48}$, Nafion ${ }^{\circledR 49-66}$, grafite $^{67}$, acetato de celulose ${ }^{68,69}$ e outros polímeros ${ }^{70,71}$, têm sido utilizados como membrana porosa nos desacopladores. Paládio metálico também tem se mostrado eficiente no desacoplamento, como têm demonstrado Kok e colaboradores ${ }^{72-77}$. A corrosão do capilar de sílica com HF foi proposta na construção de um desacoplador diretamente sobre o capilar de separação $0^{78,79}$. Neste caso, a redução da espessura da parede do capilar para $20 \mu \mathrm{m}$ resultou em uma resistência de $1,5 \times 10^{9} \Omega$, o que se mostrou suficiente na condução da corrente eletroforética.

\section{MODOS DE DETECÇÃo ELETROQUÍMICA}

\section{Detecção Condutométrica (CD)}

A CD empregada em CE teve como origem trabalhos aplicados à isotacoforese (ITP), há cerca de $30 \operatorname{anos}^{80}$. A técnica envolve, na sua versão mais simplificada, a aplicação um sinal senoidal, da ordem de milhares de hertz, a dois microeletrodos de platina posicionados adequadamente sobre o capilar. A corrente alternada que flui pelos eletrodos relaciona-se com as dimensões da cela condutométrica e com a condutância da solução entre os eletrodos e, conseqüentemente, com a composição iônica da solução analisada. Como a corrente medida é uma propriedade da solução, nenhuma seletividade é encontrada neste tipo de detecção, o que, de certa forma, é uma vantagem quando aplicada a técnicas de separação. 
Em 1979, em um trabalho de fundamental importância para a técnica de $\mathrm{CE}$, Mikkers e colaboradores ${ }^{3}$ utilizaram um detector baseado na medida do potencial desenvolvido entre dois eletrodos inseridos no capilar. Isto é, de fato, uma medida indireta da condutividade do meio eletrolítico entre os eletrodos, uma vez que o campo elétrico que recai sobre as zonas é proporcional à sua resistência elétrica. Nesse trabalho pioneiro, foi demonstrada a separação de diversos ânions orgânicos e inorgânicos em capilar de poli(tetrafluoretileno) de $200 \mu \mathrm{m}$ (d. i.).

Durante as décadas de 80 e 90 do século XX, muitos trabalhos foram publicados abordando aspectos teóricos, construção e aplicações de detectores condutométricos em CE. Já em 1985, Deml e colaboradores ${ }^{81}$ demonstraram a utilidade de dispositivos amostradores para eletroforese capilar de zona (CZE), onde as zonas eram detectadas com o auxílio de detectores condutométricos.

O primeiro trabalho dirigido para a construção e aplicação da CD em CZE data de 1986. Foret e colaboradores ${ }^{82}$ construíram siste- $^{-}$ ma duplo de detecção, empregando um detector condutométrico e um fotométrico com fibra óptica. Em 1987, Zare e colaboradores ${ }^{83}$ inseriram microeletrodos de platina de $25 \mu \mathrm{m}$ de diâmetro em capilares de 50 e $75 \mu \mathrm{m}$ perfurados com o auxílio de laser de $\mathrm{CO}_{2}$. Foi reportado o LOD de $10^{-7} \mathrm{~mol} / \mathrm{L}$ para $\mathrm{Li}^{+}$, com resposta linear por 3 ordens de grandeza, em uma cela condutométrica com volume de apenas 30 pL. Em 1991, foram propostas modificações no formato da cela condutométrica e um detector posicionado na extremidade do capilar foi implementado ${ }^{84,85}$.

De maneira a aumentar a sensibilidade da CD em CE, Dasgupta e $\mathrm{Bao}^{86}$ e Avdalovic e colaboradores ${ }^{87}$ propuseram, paralelamente, o uso de um trocador iônico acoplado ao capilar, para eliminar a condutividade residual, em um dispositivo equivalente à coluna supressora introduzida para cromatografia de íons. Um estudo mais sistemático das condições de separação para detecção condutométrica com supressão foi feito por Avdalovic e colaboradores ${ }^{88}$ e por Dasgupta e $\operatorname{Kar}^{89}$. Posteriormente, Dasgupta e Kar utilizaram seu sistema na determinação de espécies gasosas ${ }^{90}$.

Outros tipos de detectores condutométricos foram propostos. Dasgupta e colaboradores ${ }^{91}$ propuseram a utilização de dois fios paralelos alinhados no capilar e de um detector condutométrico bipolar com pulso gerado por computador. Müller e colaboradores ${ }^{92}$ construíram uma cela condutométrica onde um dos eletrodos foi depositado sobre a saída do capilar. Zare e colaboradores ${ }^{93}$ desenvolveram um detector com terra flutuante, e embora o desempenho desta versão seja inferior à anterior ${ }^{83}$, este circuito evita a interferência dos altos potenciais utilizados na separação. Também com o intuito de eliminar o problema de interferência do campo elétrico utilizado na separação, Tuma e colaboradores ${ }^{94}$ propuseram um detector condutométrico convencional onde a saída do capilar é colocada em contato com o eletrólito no compartimento através de uma fita plástica hidrofílica. Vaireanu e colaboradores ${ }^{95}$ construíram um detector condutométrico com resposta em freqüência, cujo bom isolamento entre os eletrodos e o circuito de medição, proporcionado por acoplamento capacitivo, torna o detector aplicável a eletroseparações.

A CD tem encontrado diversas aplicações em CE, principalmente após o lançamento no mercado de aparelhos munidos de $\mathrm{CD}^{96,97}$. A determinação do fluxo eletroosmótico ${ }^{98}$ e o estudo dos seus modificadores $^{99}$, bem como a determinação da mobilidade de monoaminas ${ }^{100}$ e a previsão do formato de picos ${ }^{101}$, têm sido conduzidas com o auxílio deste tipo de detecção.

Uma grande variedade de amostras tem sido analisadas, como pode ser demonstrado na determinação de ânions em matrizes ambientais $^{102-108}$, bebidas ${ }^{109-111}$, banhos para eletrodeposição ${ }^{112-114} \mathrm{e}$ peróxido de hidrogênio ${ }^{115}$, íons inorgânicos em amostras de fluido pulmonar ${ }^{116}$, cátions em fármacos ${ }^{117} \mathrm{e}$ em túbulos renais de ratos in vivo ${ }^{118}$. Além disso, surfactantes têm sido separados e detectados indiretamente ${ }^{119,120}$ e a degradação por bactérias tem sido caracterizada pela análise de espécies contendo enxofre na sua estrutura ${ }^{121}$. Particularmente interessante é a análise de traços por CE com CD. Kaniansky e colaboradores ${ }^{122}$ empregaram o acoplamento das técnicas de ITP e CZE na determinação de ânions como micro-constituintes em água de chuva. Haber e colaboradores utilizaram a isotacoforese transiente (t-ITP) para pré-concentração de ânions presentes em água de reatores nucleares ${ }^{123}$. Utilizando adição de padrão, foram obtidos ótimo limite de detecção e boa reprodutibilidade, mesmo para injeção eletrocinética de amostra.

Considerações teóricas sobre o sistema de detecção condutométrica foram conduzidas por Katzmayar e colaboradores ${ }^{124}$ a respeito da otimização do tampão de corrida para detecção condutométrica em CE. Os autores encontraram que as diferenças de condutância e a relação sinal-ruído são dependentes não somente das diferenças de mobilidade entre o analito e o co-1́on do tampão, mas também do contra-íon utilizado. Lucy e $\mathrm{Wu}^{125}$ consideraram os aspectos de calibração e de sensibilidade obtida para detecção direta e indireta para detecção condutométrica em CE.

Recentemente, a detecção condutométrica sem contato (CCD), ou detecção oscilométrica, tem recebido atenção como alternativa à detecção condutométrica convencional. Neste tipo de detecção, um sinal alternado de alta freqüência é aplicado a dois ou quatro eletrodos na cela de detecção. Como a reatância capacitiva diminui com o aumento da frequiência, a impedância do capilar é reduzida, permitindo que as variações de condutividade da solução no interior do capilar sejam observadas mesmo com os eletrodos posicionados do lado externo do capilar. Este arranjo previne a contaminação e o desgaste dos eletrodos, além de eliminar a interferência dos altos potenciais utilizados na separação. Em condições normais a CCD oferece sensibilidade superior à detecção indireta por absorção no UV-vis, com a vantagem adicional de não requerer a abertura de janelas no capilar, aumentando a sua durabilidade e facilitando a sua utilização. Zemann e colaboradores ${ }^{126}$ e Fracassi da Silva e Lago ${ }^{127}$ descreveram a utilização de detecção oscilométrica em CZE, na forma de protótipos operando a $20 \mathrm{ou} 40 \mathrm{kHz}$ e $600 \mathrm{kHz}$, respectivamente. A influência do diâmetro interno do capilar na resposta do detector foi considerada por Mayrhofer e colaboradores ${ }^{128}$. Kaniansky e colaboradores ${ }^{129}$ avaliaram alguns parâmetros do CCD proposto, como a característica de resposta, o ruído branco e sensibilidade. Os autores também aplicaram seu sistema na detecção de ânions utilizando $\alpha$-ciclodextrina para promover a separação ${ }^{130}$ e na caracterização da pureza de derivados da $\beta$-ciclodextrina ${ }^{131}$. Fracassi da Silva e Lago $^{132}$ utilizaram detecção oscilométrica na detecção de álcoois alifáticos separados por cromatografia eletrocinética micelar (MEKC) demonstrando, pela primeira vez, a possibilidade de detecção condutométrica de espécies não iônicas, sem a necessidade de qualquer tipo de modificação na molécula.

\section{Detecção Amperométrica (AD)}

$\mathrm{Na} \mathrm{AD}$, um potencial constante (em relação a um eletrodo de referência) é aplicado a um microeletrodo de trabalho. Configurações da cela eletroquímica envolvendo dois ou três eletrodos são comumente encontradas. São passíveis de análise todas as espécies eletroativas no potencial de trabalho selecionado, embora seja possível operar no modo indireto ${ }^{36,47}$, ou seja, o tampão de corrida apresentando eletroatividade. Devido à alta sensibilidade e seletividade conseguidas, e à simplicidade do arranjo experimental, a $\mathrm{AD}$ tem sido a técnica eletroquímica mais empregada em CE.

Várias células eletroquímicas e arranjos de eletrodos têm sido propostos $^{133-140}$. Sistemas mais sofisticados envolvendo a remoção 
de oxigênio ${ }^{141}$ ou o acoplamento direto de CE à diálise in vivo ${ }^{38}$ também podem ser encontrados na literatura. Eletrodos de trabalho de dimensões maiores foram avaliados por Matysik e colaboradores ${ }^{27} \mathrm{e}$ por Ye e Baldwin ${ }^{142}$. Durgbanshi e Kok ${ }^{76}$ propuseram a utilização de uma cela convencional com eletrodo de disco de $1 \mathrm{~mm}$ de diâmetro.

Celas com sistema duplo de eletrodos de trabalho foram propos$\operatorname{tas}^{35,36,143-147}$ e possuem a possibilidade de redução e oxidação simultânea dos analitos, o que pode ser bastante útil na identificação dos picos. Chen e colaboradores ${ }^{144}$ demonstraram ser possível diminuir o LOD, para espécies que possuam reações de eletrodo reversíveis, através de ciclos de oxidação e redução. Deste modo, para a mesma molécula de analito, a corrente é medida várias vezes, aumentando o sinal analítico. Recentemente, e do mesmo modo que os sistemas com dois eletrodos, celas eletroquímicas contendo eletrodos de trabalho interdigitados têm oferecido amplas possibilidades de detecção ${ }^{65,66,148-150}$. Slater e Watt ${ }^{151}$ construíram um arranjo de oito microeletrodos de banda sobre um substrato de silício, utilizando técnicas de microfabricação, e acoplaram a um sistema de CE convencional.

Jin e Chen derivaram equações para a corrente desenvolvida em eletrodos de disco ${ }^{152}$ e a respectiva eficiência coulométrica ${ }^{153}$, para a configuração EndC. Ambos trabalhos foram endossados experimentalmente.

Uma vez que a eletroatividade é o requisito básico para a resposta nos sistemas amperométricos, uma grande variedade de compostos tem sido analisada por AD. Uma das principais áreas de aplicação da $\mathrm{AD}$ é a análise de compostos de interesse biológico, como neurotransmissores ${ }^{42-46,48,58,79,154-156}, \quad$ aminoácidos $^{34,50,53,157-159}$, peptídeos $^{40,52,157}$, enzimas e proteínas ${ }^{160-162}$, co-fatores ${ }^{163}$, nucleotídeos e similares ${ }^{164-166}$, ácidos policarboxílicos ${ }^{167}$, hormônios ${ }^{168}$, bem como outros metabólitos, como ácido úrico ${ }^{169,170}$ e glutationa ${ }^{171}$. Outras classes de compostos envolvem fármacos, como antibióticos, antialérgicos, vitaminas, analgésicos, anestésicos, etc ${ }^{31,53,59,67,172-185}$, compostos de interesse ambiental - incluindo clorofenóis ${ }^{75,186-188}$, aminas aromáticas ${ }^{77,189}$, mercúrio ${ }^{190}$, explosivos ${ }^{191,192}$ e ânions ${ }^{193,194}$ peróxidos ${ }^{195}$, metais de transição ${ }^{196}$ e carboidratos, alditóis e similares $^{197-201}$

A ED também é bastante apropriada em separações eletroforéticas em meio não-aquoso (NACE), uma vez que a maioria dos solventes utilizados absorve fortemente na região do UV, o que dificulta as medidas fotométricas. Com efeito, AD tem sido aplicada com sucesso em técnicas de $\mathrm{NACE}^{202-208}$. Separações quirais são de grande interesse em análises clínicas e na indústria farmacêutica e, nestes casos, a AD também tem estado presente $\mathrm{e}^{62,209,210}$.

Uma ampla variedade de materiais (e dimensões) tem sido empregada na fabricação dos microeletrodos. Há na literatura a descrição de eletrodos confeccionados com fibra ${ }^{40-50,64,155,168,170,173,175-}$ $177,179,183,187,189,193$ e disco de carbono ${ }^{154,156,178,180,181,184,185}$, carbono vítreo $^{76,77}$, platina ${ }^{27,28,36,37,57,143,147,202-208}$, cobre ${ }^{34,142,157,158,160,165,167,197-199,210}$, níquel $^{200,201}$ e ouro ${ }^{66,144,145,147,148,182,188,190-192,194,195}$. Eletrodos modificados oferecem diferentes possibilidades de detecção, como, por exemplo, a diminuição dos potenciais de oxidação ou redução de diversas espécies. Eletrodos de filme de mercúrio depositados em ouro são bastantes atrativos, devido à simplicidade de construção e ampliação da faixa de potencial negativo de trabalho ${ }^{32,141,146,152,153,171,211,212}$. A deposição de filme de estanho sobre platina proporcionou aumento de sensibilidade na análise de clorofenóis, além de evitar o bloqueio do eletrodo ${ }^{186}$. Wang e colaboradores têm utilizado deposição de partículas de platina ${ }^{54}$ e paládio ${ }^{60,61}$ sobre fibra de carbono. Eletrodos modificados com rutênio de valência mista têm sido aplicados na determinação de compostos com grupos sulfeto ${ }^{69,213}$ e espécies nãoeletroativas ${ }^{214}$. Vários compostos podem ser determinados em eletrodos modificados com ftalocianinas de cobalto ${ }^{69,74,215,216}$. Outros tipos de modificação envolvem a utilização de óxido de cobre ${ }^{73}$, enzimas $^{149,215}$, polímeros ${ }^{217,218}$, além da atividade catalítica de 4-piridilhidroquinona na determinação de hidrazinas ${ }^{174,219}$.

A detecção amperométrica pulsada (PAD) difere da AD operando em potencial constante apenas pela utilização de vários degraus de potencial, que são utilizados na limpeza, condicionamento e préconcentração de analitos sobre a superfície do eletrodo. Como uma ampla combinação de pulsos pode ser gerada, a PAD estende consideravelmente o número de aplicações, além de proporcionar ótimos limites de detecção e aumentar a reprodutibilidade do sistema de detecção e o tempo de vida dos eletrodos.

PAD com eletrodos de cobre ou ouro tem sido largamente aplicada na análise de carboidratos ${ }^{220-227}$. Além disso, PAD pode ser utilizada com sucesso na análise de íons metálicos ${ }^{228,229}$, aminoglicosídeos ${ }^{230}$, aminoácidos ${ }^{226}$ e compostos com grupos contendo enxofre 226,231 .

\section{Detecção Potenciométrica (PD)}

Em termos gerais, a PD possui características que a situa entre as técnicas amperométrica e condutométrica, principalmente quando se compara a seletividade e os LOD conseguidos com esta técnica (tipicamente $10^{-6}$ a $10^{-8} \mathrm{~mol} / \mathrm{L}$ ). A resposta dos eletrodos potenciométricos é diretamente proporcional à concentração (ou mais corretamente à atividade) dos analitos que permeiam através de uma membrana ou filme seletivos, e é relativa ao sinal residual atribuído ao tampão ou eletrólito de corrida, levando-se em consideração os coeficientes de seletividade. Devido à característica logarítmica do potencial desenvolvido nas membranas, uma ampla faixa dinâmica é encontrada para este modo de detecção. Com a utilização de eletrodos de dimensões reduzidas, o tempo de resposta destes sensores se mostrou apropriado para aplicações em CE.

O fato do campo elétrico utilizado na separação causar um deslocamento no potencial dos eletrodos seletivos não foi crucial para o desempenho dos sistemas de detecção - todos os artigos envolvendo PD relatam a utilização do arranjo EndC.

Eletrodos de membrana líquida foram inicialmente emprega$\operatorname{dos}^{232-238}$, mas devido à sua fragilidade e dificuldade de implementação, têm sido substituídos por eletrodos metálicos recobertos com filme seletivo ${ }^{33,239-246}$. Estes possuem maior robustez, facilidade de alinhamento e fabricação, além de possuírem maior tempo de vida e nível de resposta comparável com os eletrodos de membrana líquida. Eletrodos de cobre metálico (eletrodos de primeira ordem) têm sido utilizados na detecção potenciométrica de aminoácidos ${ }^{244,247}$, agentes quelantes $^{248} \mathrm{e}$ ânions orgânicos e inorgânicos ${ }^{249}$.

A maior parte das aplicações refere-se à detecção de cátions ${ }^{33,232-}$ 234,238,240-242,244 e ânions ${ }^{235-237,240-242,245,248,249}$ inorgânicos e orgânicos comuns, embora haja descrita a detecção de aminoácidos, como destacado acima, neurotransmissores ${ }^{246}$ e ácidos carboxílicos de cadeia linear com até 10 carbonos $^{239,243}$. Zakaria e colaboradores ${ }^{250}$ propuseram um método de detecção potenciométrica pulsada para a análise de diversos ânions.

\section{Detecção Voltamétrica (VD)}

Com o desenvolvimento dos sistemas rápidos de aplicação de potencial e leitura da corrente ("fast scan voltametry") tornou-se possível a aplicação da voltametria (VD) em CE.

$\mathrm{A} \mathrm{VD}$ possui sensibilidade semelhante à $\mathrm{AD}$ aliada à possibilidade de identificação dos picos, devido à resposta voltamétrica característica de cada analito isolado. Isto se torna importante quando ocorre a co-migração das zonas, ou quando se necessita verificar a pureza de determinado pico. 
Nota-se na literatura que os sistemas voltamétricos foram sendo aperfeiçoados ao longo dos anos, desde o seu aparecimento em 1994, na forma de um sistema simples de varredura de potencial ${ }^{251}$. Em 1996, Ewing e colaboradores ${ }^{252}$ utilizariam este mesmo sistema de varredura na caracterização de diferentes compartimentos vesiculares em um único neurônio, através do monitoramento da dopamina contida nestes compartimentos.

Sistemas voltamétricos foram também utilizados por Lunte e colaboradore $^{253}$ na detecção e diferenciação de ácidos fenólicos separados por CE. Aqui foi empregado desacoplador de Nafion ${ }^{\circledR}$ com a finalidade de minimizar a interferência do campo elétrico de separação e as distorções causadas nos voltamogramas devido à queda de potencial na resistência da solução ("IR drop").

Sendo uma técnica voltamétrica extremamente rápida, a voltametria de onda quadrada ("square-wave voltametry, SWV") é especialmente apropriada como método de detecção para sistemas em fluxo. Gerhardt e colaboradores primeiramente demonstraram a potencialidade da técnica na detecção de dopamina e epinefrina ${ }^{254}$. Gerhardt e colaboradores ampliaram a gama de compostos passíveis de análise voltamétrica pela utilização de SWV por adsorção ${ }^{255}$. Vários compostos, incluindo fármacos $\beta$-agonistas, antibióticos e aminoácidos foram previamente adsorvidos em eletrodo de platina com pulsos de pré-varredura para posterior dessorção. Os processos de adsorção-dessorção no eletrodo geram curvas características para cada espécie adsorvida e a amostragem da corrente em vários intervalos de tempo é útil nestes casos para a caracterização e diferenciação dos analitos. Além disso, potenciais extremamente negativos foram aplicados sem a prévia remoção do oxigênio dissolvido. SWV com transformada de Fourier rápida (FFTSWV), utilizando microeletrodos de platina ou ouro, foi aplicada na análise de uma série de derivados da fenotiazina ${ }^{256}$. Neste tipo de técnica, vários processos envolvendo os analitos, como reações de oxidação e redução, adsorção e dessorção, modificação da superfície do eletrodo, inibição das ondas do oxigênio e hidrogênio e variações na resistência da solução tomam parte na resposta sistema.

Metais de transição foram separados por CE e detectados utilizando-se voltametria cíclica $(\mathrm{CV})^{257,258}$. Através de pulsos pré-varredura, Cassidy e colaboradore ${ }^{257}$ efetuaram, além da limpeza e condicionamento dos eletrodos, a pré-concentração dos metais de transição. LOD na faixa de $10^{-9}$ a $10^{-8} \mathrm{~mol} / \mathrm{L}$ foram conseguidos com esta técnica, com a vantagem adicional da identificação das espécies que co-migram. Cassidy e colaboradores ${ }^{258}$ utilizaram $\mathrm{CV}$ e PAD com onda quadrada. Neste trabalho, a análise do segundo harmônico da resposta proporcionou maior estabilidade da linha base, em detrimento do LOD. A análise do ângulo de fase do sinal permitiu a separação das correntes capacitiva e faradaica. LOD na faixa de $10^{-8}$ a $10^{-7} \mathrm{~mol} / \mathrm{L}$ foram conseguidos sem a remoção de oxigênio em potenciais extremamente negativos utilizando eletrodo de ouro ou platina.

CV rápida de redução foi utilizada por Cassidy e colaboradores $^{259,260}$ na determinação de alguns antibióticos pré-concentrados em eletrodos de filme de mercúrio. LOD na faixa de $10^{-7}$ a $10^{-6} \mathrm{~mol} / \mathrm{L}$ foram obtidos para tetraciclina e derivados ${ }^{259}$ e $10^{-7} \mathrm{~mol} / \mathrm{L}$ para antibióticos glicoconjugados ${ }^{260}$.

\section{SEPARAÇÕES EM $\mu$ CHIPS}

Separações em $\mu$ chips têm recebido crescente atenção da comunidade científica desde o seu aparecimento, na última década do século XX. Sistemas baseados em $\mu$ chips podem integrar vários processos em um único substrato, tais como etapas de pré-concentração, derivatização, amplificação de DNA por reação com enzima polimerase (PCR, "Polimerase Chain Reaction"), mistura, diluição, separação e detecção. Devido às dimensões dos canais empregados, volumes muito pequenos de amostra e reagentes são consumidos e separações extremamente rápidas são conseguidas.

A quantidade reduzida de amostra introduzida obviamente impõe limitações ao sistema de detecção. De fato, fluorescência induzida por laser (LIF), ou ainda espectrometria de massas, têm sido empregadas neste sentido, embora outros métodos ópticos possam ser adaptados. Como resultado, obtém-se separações em escala milimétrica, mas os sistemas de detecção limitam a sua aplicação em ambientes reduzidos. Devido às suas características, a ED é particularmente apropriada como sistema de detecção em $\mu$ chips. Como vantagem adicional, o processo de fabricação dos detectores eletroquímicos pode ser completamente integrado ao processo de fabricação dos uchips.

Gavin e Ewing demonstraram a utilização de uma matriz de 100 eletrodos de platina, endereçados individualmente e construídos através de técnicas de fotolitografia sobre um substrato de vidro. O sistema de separação, denominado eletroforese em canal, permitiu a resolução em duas dimensões do analito entregue por um capilar de amostragem, posicionado na abertura do canal ${ }^{261-263}$.

O processo de fabricação dos $\mu$ chips e sistema de detecção foi primeiramente proposto por Wooley e colaboradores ${ }^{264}$, onde foi demonstrada a separação de três neurotransmissores em 100 s. Wang e colaboradores ${ }^{265}$ depositaram por "sputtering" um filme fino de ouro na saída do canal de separação e o utilizaram como eletrodo de trabalho, eliminando os problemas envolvidos no alinhamento. A mesma aproximação foi conduzida por Hilmi e Luong ${ }^{266}$, mas pela utilização de deposição química de ouro catalisada na superfície do substrato de vidro. Eletrodos impressos de carbono têm sido uma boa alternativa na construção de detectores eletroquímicos em $\mu$ chips $^{267-272}$. Wang e colaboradores ${ }^{267-271}$ demonstraram a potencialidade da utilização de eletrodos impressos removíveis, pela facilidade de troca de eletrodos passivados ou modificados, eliminando a necessidade de troca do sistema completo de separação e reduzindo os custos de confecção do sistema total. Materiais diversos têm sido empregados na construção dos $\mu$ chips, como polímeros ${ }^{272,273}$ e cerâmica $^{274}$. Rossier e colaboradores ${ }^{272}$ construíram um $\mu$ chip em poli(etilenotereftalato) (PET) utilizando técnicas de ablação por laser. Um desacoplador simples, que utiliza micro-aberturas no material polimérico foi construído antes do sistema de detecção baseado em um eletrodo impresso de carbono. Sistemas duplos de detecção também foram propostos para separações em $\mu$ chip $^{273}$.

As aplicações de $\mu$ chips com ED estendem-se à separação de neurotransmissores ${ }^{261-267,272-274}$, explosivos nitroaromáticos ${ }^{266,267,275}$, acetaminofeno $^{268}$ ácidos úrico ${ }^{268}$ e ascórbico ${ }^{268,273}$. Estratégias de reação enzimática ${ }^{268}$ e derivatização acoplada ao canal de separação ${ }^{269}$ foram empregadas na determinação de glicose e aminoácidos, respectivamente. Além disso, foi efetuada a detecção indireta de fragmentos de DNA, separados por eletroforese em gel (CGE), a qual nunca havia sido utilizada com ED $\mathrm{ED}^{264,276}$. Detecção voltamétrica também foi aplicada no formato de $\mu$ chip, na determinação de catecol, hidrazina, trinitrotolueno e níquel ${ }^{277}$.

\section{APLICAÇÕES}

Como se verificou nos itens anteriores, a detecção eletroquímica tem sido aplicada a diversas classes de compostos, nas mais variadas matrizes. De modo a fornecer uma referência rápida, estão compiladas na Tabela 1 algumas das aplicações envolvendo ED em CE. A faixa de valores contidos na coluna limite de detecção (LOD) referese aos limites mínimo e máximo encontrados em $\mu \mathrm{mol} / \mathrm{L}$. Alguns valores foram deixados em ppm, ppb ou fmol, de acordo com as informações fornecidas nos artigos consultados. 
Tabela 1. Resumo das aplicações envolvendo detecção eletroquímica em eletroforese capilar

\begin{tabular}{|c|c|c|c|c|}
\hline Analito & Modo $^{\mathrm{a}, \mathrm{b}}$ & $\mathrm{LOD}^{\mathrm{c}}$ & Referência & Matriz \\
\hline \multirow[t]{2}{*}{ Ácido Ascórbico } & $\mathrm{AD}$ & 0,1 & $35,140,143,216$ & \\
\hline & $\mu$ chip & 5 & 268,273 & \\
\hline Ácido Barbitúrico & $\mathrm{AD}$ & $0,1-0,5$ & 175 & \\
\hline Ácidos Carboxílicos & $\mathrm{PD}$ & $0,004-40$ & $239,243,245$ & \\
\hline \multirow[t]{2}{*}{ Ácidos Fenólicos } & $\mathrm{AD}$ & $0,001-4,7$ & $35,55,63,76,143$ & Bebidas $(35,63,143)$ \\
\hline & VD & $0,2-1,3$ & 253 & \\
\hline Ácidos Fosfônicos & $\mathrm{CD}$ & $6-75 \mathrm{ppb}$ & 106,107 & Água, solo \\
\hline Ácido Oxálico & $\mathrm{AD}$ & 0,12 & 216 & Urina \\
\hline \multirow[t]{2}{*}{ Ácidos Policarboxílicos } & $\mathrm{AD}$ & $0,5-3,9$ & 140,167 & \\
\hline & $\mathrm{PD}$ & & 248 & \\
\hline \multirow[t]{2}{*}{ Ácido Úrico } & $\mathrm{AD}$ & 0,13 & $169,170,216$ & Urina(169,170,216),soro $(170)$ \\
\hline & $\mu \mathrm{chip}$ & 5 & 268 & \\
\hline \multirow[t]{2}{*}{ Álcoois } & $\mathrm{AD}$ & $0,6-12 \mathrm{fmol}$ & 201 & \\
\hline & $\mathrm{CD}$ & $800-5300$ & 132 & \\
\hline Aminas Aromáticas & $\mathrm{AD}$ & $0,01-1,2$ & 77,148 & Água(77) \\
\hline \multirow[t]{4}{*}{ Aminoácidos } & $\mathrm{AD}$ & $0,01-400$ & $\begin{array}{c}34,50,58,69,76,146,157-159 \\
169,211,226\end{array}$ & $\begin{array}{l}\text { Urina }(146,157,169,211) \\
\quad \text { celular(159) }\end{array}$ \\
\hline & PD & $3,2-5,9$ & 244,247 & dialisado(58), soro(211) \\
\hline & VD & 1 & 255 & Hidrolisado (158) \\
\hline & $\mu \mathrm{chip}$ & 2,5 & 269,273 & \\
\hline Anfetaminas & $\mathrm{AD}$ & $0,012-0,017$ & 208 & \\
\hline \multirow[t]{3}{*}{ Ânions } & $\mathrm{AD}$ & $0,001-10$ & $193,194,196,202$ & Urina(96), fármacos(241,280), \\
\hline & $\mathrm{CD}$ & $0,27-1,4$ & $\begin{array}{c}3,86-88,96,103-105,108116, \\
119,122-126,129,130,279,280\end{array}$ & $\begin{array}{c}\text { Bebidas }(86,87,96,109,110,130,241), \\
\text { água(103-105,236), solo(129), } \\
\text { banho de deposição(112-114) }\end{array}$ \\
\hline & $\mathrm{PD}$ & $0,01-381$ & $235-237,240-242,245,249,250$ & \\
\hline \multirow[t]{2}{*}{ Antibióticos } & $\mathrm{AD}$ & $0,9-17$ & $177,180,230$ & Fármacos(230), soro(177) \\
\hline & VD & $0,01-0,3$ & $255,259,260$ & Urina(180) \\
\hline Arsênio,derivados & $\mathrm{CD}$ & $60 \mathrm{ppb}$ & 102 & Água \\
\hline Aspartame & $\mathrm{AD}$ & 100 & 157 & Bebidas \\
\hline$\beta$-agonistas & VD & 0,01 & 255 & \\
\hline$\beta$-bloqueadores & $\mathrm{AD}$ & 0,01 & 155 & \\
\hline \multirow[t]{2}{*}{ Carboidratos, Alditóis } & $\mathrm{AD}$ & $0,08-5$ & $\begin{array}{c}28,73,139,140,142,169,197,198 \\
200,201,215,220-227\end{array}$ & $\begin{array}{l}\text { Urina }(169,200), \text { sangue }(220), \\
\text { bebidas }(200)\end{array}$ \\
\hline & $\mu \mathrm{chip}$ & 6 & 268 & \\
\hline \multirow[t]{3}{*}{ Cátions } & $\mathrm{AD}$ & 0,02 & 214 & Bebidas(238,241), saliva(96) \\
\hline & $\mathrm{CD}$ & $0,1-9,5$ & $83,87,93,96,116-118,126,127,278$ & $\operatorname{soro}(233,278)$ \\
\hline & PD & $0,0001-10$ & $33,232-234,238,240,241,244$ & fármacos(117,241) \\
\hline Clorofenóis & $\mathrm{AD}$ & $0,02-0,5$ & $75,76,186-188,206$ & Água, solo(186,188) \\
\hline Clozapina & $\mathrm{AD}$ & 0,42 & 31 & Sangue \\
\hline Corantes & $\mathrm{AD}$ & 7,4 ppb & 203,204 & Tinta \\
\hline Diclofenaco & $\mathrm{AD}$ & 2,5 & 176 & Urina \\
\hline Dissulfetos & $\mathrm{AD}$ & $0,5-100$ & $145,146,213,215,231$ & Urina(146,213) \\
\hline DNA & $\mu \mathrm{chip}$ & 264,276 & & \\
\hline \multirow[t]{2}{*}{ Explosivos } & $\mathrm{AD}$ & $70-300 \mathrm{ppb}$ & 191,192 & Água, solo(191,192,275) \\
\hline & $\mu$ chip & $24-200$ & $266,267,275$ & \\
\hline Ferroceno, deriv. & $\mathrm{AD}$ & $0,04-3$ & $27,57,148,203$ & \\
\hline \multirow[t]{2}{*}{ Fenol, deriv. } & $\mathrm{AD}$ & $0,2-2,5 \mathrm{ppm}$ & $71,140,147$ & Água(271) \\
\hline & $\mu \mathrm{chip}$ & $1-2$ & 271 & \\
\hline Fenotiazina,deriv. & VD & 0,1 & 256 & \\
\hline Flavonóides & $\mathrm{AD}$ & $0,06-0,55$ & $181,183-185$ & $\begin{array}{l}\text { Urina(183), drogas }(184,185) \\
\text { extrato vegetal }(181,185)\end{array}$ \\
\hline Glutationa & $\mathrm{AD}$ & $0,1-0,63$ & 171,212 & Sangue, celular \\
\hline \multirow[t]{2}{*}{ Hidrazinas } & $\mathrm{AD}$ & $1-18,5$ & $54,60,174,215,218,219$ & Urina $(60)$ \\
\hline & $\mu \mathrm{chip}$ & 1,5 & 270 & \\
\hline Hidroquinona & $\mathrm{AD}$ & $0,005-0,02$ & $55,78,151$ & \\
\hline Hidroxilamina & $\mathrm{AD}$ & 0,05 & 61 & Água, efluente \\
\hline Melatonina & $\mathrm{AD}$ & $0,001-1,3$ & 168,178 & Glândula(168), cápsulas(168,178) \\
\hline Metais transição & $\mathrm{AD}$ & $0,009-38,5$ & $141,190,196,228,229$ & Sedimentos $(190)$ \\
\hline & $\mathrm{CD}$ & 96 & & \\
\hline & VD & $0,005-0,2$ & 257,258 & \\
\hline Metronidazol & $\mathrm{AD}$ & $0,4-38$ & 141,182 & Urina(182) \\
\hline $\mathrm{NADH}$ & $\mathrm{AD}$ & 1 & 35 & \\
\hline Neuropeptídeos & $\mathrm{AD}$ & $0,05-1$ & 40 & Soro \\
\hline Neurotransmissores & $\mathrm{AD}$ & $0,004-2,9$ & $\begin{array}{c}28,42-46,48,55,65,72,76,78,79,133,134 \\
137-139,143,144,150,151,154,156\end{array}$ & $\begin{array}{l}\text { Celular( } 43,48,154,252) \\
\quad \text { dialisado(79) }\end{array}$ \\
\hline & PD & $0,6-40$ & 246 & \\
\hline & VD & $2,3-6,6$ & $251,252,254$ & \\
\hline & $\mu \mathrm{chip}$ & $0,38-5,5$ & $261-265,267,272-274$ & \\
\hline Nicotina & $\mathrm{AD}$ & 1,5 & 38,205 & Dialisado, tabaco \\
\hline Nucleotídeos, nucleosídeos & $\mathrm{AD}$ & $0,36-5$ & $69,140,164,165$ & \\
\hline Peptídeos & $\mathrm{AD}$ & $0,7-5,5$ & $52,157,225$ & \\
\hline Peróxidos & $\mathrm{AD}$ & 10 & 195 & \\
\hline
\end{tabular}


Tabela 1. continuação

\begin{tabular}{|c|c|c|c|c|}
\hline Analito & Modo $^{\mathrm{a}, \mathrm{b}}$ & $\mathrm{LOD}^{\mathrm{c}}$ & Referência & Matriz \\
\hline Polissacaríseos & $\mathrm{AD}$ & $0,1-1$ & 199 & \\
\hline Prometazina & $\mathrm{AD}$ & $0,01-0,93$ & 32,173 & Soro(32), urina(173) \\
\hline Proteínas, enzimas & $\mathrm{AD}$ & $0,0001-0,4$ & $160-162$ & Soro bovino(161), urina(162) \\
\hline Reserpina & $\mathrm{AD}$ & 0,8 & 179 & Soro \\
\hline Selênio, deriv. & $\mathrm{CD}$ & $60 \mathrm{ppb}$ & 102 & \\
\hline Surfactantes & $\mathrm{CD}$ & $1-38$ & $96,119,120,125$ & \\
\hline Vitaminas & $\mathrm{AD}$ & $0,2-2,7$ & $35,67,178$ & Cápsulas(178) \\
\hline Tióis & $\mathrm{AD}$ & $0,021-5$ & $51,74,145,213,215,226,231$ & \\
\hline Tioridazina & $\mathrm{AD}$ & 0,01 & 173 & Urina \\
\hline
\end{tabular}

a. Modos de detecção: AD - Amperométrica; CD - Condutométrica; PD - Potenciométrica; VD - Voltamétrica;

b. $\mu$ chip se refere a separação efetuada em microchip com detecção amperométrica;

c. limites de detecção em mmol/l, exceto quando indicado;

Deriv. - Derivados; Soro, isoladamente, refere-se ao soro sangüíneo humano.

\section{CONCLUSÕES}

Em resumo, as técnicas eletroquímicas de detecção em conjunto com CE têm encontrado um grande campo de atuação. Após aproximadamente 20 anos de desenvolvimento sobre os sistemas de ED em $\mathrm{CE}$, hoje conta-se com uma grande variedade de montagens de detectores, e as grandes dificuldades no posicionamento do eletrodo e interferência do campo elétrico de separação foram praticamente solucionadas. Com as modalidades de técnicas eletroanalíticas disponíveis, praticamente todas as classes de compostos podem ser analisadas por CE-ED, sendo que na maioria dos casos com ótima sensibilidade, o que viabiliza aplicações em diferentes ambientes e matrizes. Técnicas seletivas, como $\mathrm{PD}$ ou $\mathrm{AD}$, têm sido utilizadas na determinação e eliminação de interferentes previamente separados por CE. Além disso, a VD possibilita a caracterização eletroquímica dos picos obtidos, fornecendo informações importantes na diferenciação dos analitos separados. Técnicas não seletivas, como a CD, por exemplo, têm sido empregadas com sucesso como estratégia universal de detecção. Por fim, devido às suas características de construção, as técnicas eletroquímicas são bastante apropriadas para a integração em sistemas montados sobre mchips, que por sua vez têm recebido muita atenção da comunidade científica, devido às novas e promissoras possibilidades analíticas.

\section{AGRADECIMENTOS}

O autor gostaria de tecer agradecimentos à N. L. Ricelli e ao Dr. C. L. do Lago pelas revisões no texto, ao Laboratório de Automação e Instrumentação Analítica (IQ-USP) pelo espaço fornecido e à FAPESP e ao CNPq pelos auxílios concedidos.

\section{REFERÊNCIAS}

1. Tavares, M. F. M.; Quim. Nova 1996, 19, 173.

2. Tavares, M. F. M.; Quim. Nova 1997, 20, 493.

3. Mikkers, F. E. P.; Everaerts, F. M.; Verheggen, Th. P. E. M.; J. Chromatogr. 1979, 169, 11.

4. Jorgenson, J. W.; Lukacs, K. D.; Anal. Chem. 1981, 53, 1298.

5. Ewing, A. G.; Wallingford, R. A.; Olefirowicz, T. M.; Anal. Chem. 1989, $61,292 \mathrm{~A}$

6. Curry, P. D.; Engstrom-Silverman, C. E.; Ewing, A. G.; Electroanalysis 1991, 3, 587.

7. Yik, Y. F.; Li, S. F. Y.; Trends Anal. Chem. 1992, 11, 325.

8. Ewing, A. G.; Mesaros, J. M.; Gavin, P. F.; Anal. Chem. 1994, 66, 527A.

9. Chen, J.-G.; Woltman, S. J.; Weber, S. G.; Adv. Chromatogr. 1996, 36, 273.

10. Möller, A.; Scholtz, F.; Fresenius J. Anal. Chem. 1996, 356, 160.

11. Buchberger, W.; Fresenius J. Anal. Chem. 1996, 354, 797.

12. O'shea, T. J.; Prog. Pharm. Biomed. Anal. 1996, $2,277$.

13. Voegel, P. D.; Baldwin, R. P.; Electrophoresis 1997, 18, 2267.
14. Holland, L. A.; Lunte, S. M.; Anal. Commun. 1998, 35, 1H.

15. Bryant, B. R.; Swanek, F. D.; Ewing, A. G.; Chem. Anal. 1998, 146, 355

16. You, T.; Yang, X.; Wang, E.; Electroanalysis 1999, 11, 459.

17. Kappes, T.; Hauser, P. C.; J. Chromatogr., A 1999, 834, 89.

18. Polesello, S.; Valsecchi, S. M.; J. Chromatogr., A 1999, 834, 103.

19. Baldwin, R. P.; J. Pharm. Biomed. Anal. 1999, 19, 69.

20. Kok, W. T.; Chromatographia 2000, 51, 73.

21. Kappes, T.; Hauser, P. C.; Electroanalysis 2000, 12, 165.

22. Matysik, F.-M.; Electroanalysis 2000, 12, 1349.

23. Wang, A.; Fang, Y.; Electrophoresis 2000, 21, 1281.

24. Baldwin, R. P.; Electrophoresis 2000, 21, 4017.

25. Nagels, L. J.; Poels, I.; Trends Anal. Chem. 2000, 19, 410.

26. Lu, W.; Cassidy, R. M.; Anal. Chem. 1994, 66, 200.

27. Matysik, F.-M.; Nyholm, L.; Markides, K. E.; Fresenius J. Anal. Chem. 1999, 363, 231.

28. Voegel, P. D.; Zhou, W.; Baldwin, R. P.; Anal. Chem. 1997, 69, 951.

29. Fermier, A. M.; Gostkowski, M. L.; Colón, L. A.; Anal. Chem. 1996, 68, 1661.

30. Kappes, T.; Hauser, P. C.; Analyst 1999, 124, 1035.

31. Jin, W.; Xu, Q.; Li, W.; Electrophoresis 2000, 21, 1415.

32. Jin, W.; Xu, Q.; Li, W.; Electrophoresis 2000, 21, 1527.

33. Kappes, T.; Hauser, P. C.; Anal. Chem. 1998, 70, 2487.

34. Zhou, J.; Lunte, S. M.; Electrophoresis 1995, 16, 498.

35. Zhong, M.; Zhou, J.; Lunte, S. M.; Zhao, G.; Giolando, D. M.; Kirchhoff, J. R.; Anal. Chem. 1996, 68, 203.

36. Holland, L. A.; Lunte, S. M.; Anal. Chem. 1999, 71, 407.

37. Wallenborg, S. R.; Nyholm, L.; Lunte, C. E.; Anal. Chem. 1999, 71, 544.

38. Zhou, J.; Heckert, D. M.; Zuo, H.; Lunte, C. E.; Lunte, S. M.; Anal. Chim. Acta 1999, 379, 307.

39. Everett, W. R.; Bohs, C.; Davies, M. I.; Curr. Sep. 2000, 19, 25.

40. Gawron, J. A.; Lunte, S. M.; Electrophoresis 2000, 21, 3205.

41. Wallingford, R. A.; Ewing, A. G.; Anal. Chem. 1987, 59, 1762.

42. Wallingford, R. A.; Ewing, A. G.; Anal. Chem. 1988, 60, 258.

43. Wallingford, R. A.; Ewing, A. G.; Anal. Chem. 1988, 60, 1972.

44. Wallingford, R. A.; Ewing, A. G.; J. Chromatogr. 1988, 441, 299.

45. Wallingford, R. A.; Ewing, A. G.; Anal. Chem. 1989, 61, 98.

46. Olefirowicz, T. M.; Ewing, A. G.; Anal. Chem. 1990, 62, 1872.

47. Olefirowicz, T. M.; Ewing, A. G.; J. Chromatogr. 1990, 499, 713.

48. Olefirowicz, T. M.; Ewing, A. G.; Chimia 1991, 45, 106.

49. O'Shea, T. J.; Greenhagen, R. D.; Lunte, S. M.; Lunte, C. E.; Smyth, M. R.; Radzik, D. M.; Watanabe, N.; J. Chromatogr. 1992, 593, 305.

50. O'Shea, T. J.; Weber, P. L.; Bammel, B. P.; Lunte, C. E.; Lunte, S. M.; Smyth, M. R.; J. Chromatogr. 1992, 608, 189.

51. O'Shea, T. J.; Lunte, S. M.; Anal. Chem. 1993, 65, 247.

52. Deacon, M.; O'Shea, T. J.; Lunte, S. M.; Smyth, M. R.; J. Chromatogr., A 1993, 652, 377.

53. Malone, M. A.; Weber, P. L.; Smyth, M. R.; Lunte, S. M.; Anal. Chem. 1994, 66, 3782

54. Zhou, W.; Xu, L.; Wu, M.; Xu, L.; Wang, E.; Anal. Chim. Acta 1994, 299, 189

55. Park, S.; Lunte, S. M.; Lunte, C. E.; Anal. Chem. 1995, 67, 911.

56. Park, S.; Lunte, C. E.; Anal. Chem. 1995, 67, 4366.

57. Matysik, F-M.; Meister, A.; Werner, G.; Anal. Chim. Acta 1995, 305, 114.

58. Malone, M. A.; Zuo, H.; Lunte, S. M.; Smyth, M. R.; J. Chromatogr., A 1995, 700, 73

59. Zhou, W.; Liu, J.; Wang, E.; J. Chromatogr., A 1995, 715, 355. 
60. Liu, J.; Zhou, W.; You, T.; Li, F.; Wang, E.; Dong, S.; Anal. Chem. 1996, $68,3350$.

61. You, T.; Wu, M.; Wang, E.; Anal. Lett. 1997, 30, 1025.

62. Hadwiger, M. E.; Park, S.; Torchia, S. R.; Lunte, C. E.; J. Pharm. Biomed. Anal. 1997, 15, 621.

63. Moane, S.; Park, S.; Lunte, C. E.; Smyth, M. R.; Analyst 1998, 123, 1931

64. Huang, X.; You, T.; Yang, X.; Wang, E.; Talanta 1999, 49, 425.

65. Liu, Z.; Niwa, O.; Kurita, R.; Horiuchi, T.; J. Chromatogr., A 2000, 891, 149.

66. Kurita, R.; Tabei, H.; Liu, Z.; Horiuchi, T.; Niwa, O.; Sens. Actuators, B 2000, 71, 82.

67. Yik, Y. F.; Lee, H. K.; Li, S. F. Y.; Khoo, S. B.; J. Chromatogr 1991, 585, 139.

68. Chen, I-C.; Whang, C-W.; J. Chromatogr. 1993, 644, 208.

69. Zhou, J.; Lunte, S. M.; Anal. Chem. 1995, 67, 13.

70. Tüdös, A. J.; Van Dyck, M. M. C.; Poppe, H.; Kok, W. Th.; Chromatographia 1993, 37, 79.

71. Zhang, S. S.; Yuan, Z. B.; Liu, H. X.; Zou, H.; Wu, Y. J.; J. Chromatogr. A 2000, 872, 259.

72. Kok, W. Th.; Sahin, Y.; Anal. Chem. 1993, 65, 2497.

73. Huang, X.; Kok, W. Th.; J. Chromatogr., A 1995, 707, 335.

74. Huang, X.; Kok, W. Th.; J. Chromatogr., A 1995, 716, 347.

75. van Bruijnsvoort, M.; Sanghi, S. K.; Poppe, H.; Kok, W. Th.; J. Chromatogr., A 1997, 757, 203.

76. Durgbanshi, A.; Kok, W. Th.; J. Chromatogr., A 1998, 798, 289.

77. Asthana, A.; Bose, D.; Durgbanshi, A.; Sanghi, S. K.; Kok, W. Th.; J. Chromatogr., A 2000, 895, 197.

78. Hu, S.; Wang, Z-L.; Li, P-B.; Cheng, J-K.; Anal. Chem. 1997, 69, 264.

79. Qian, J.; Wu, Y.; Yang, H.; Michael, A. C.; Anal. Chem. 1999, 71, 4486.

80. van der Steen, C.; Everaerts, F. M.; Verheggen, Th. P. E. M.; Poulis, J. A.; Anal. Chim. Acta 1972, 59, 298.

81. Deml, M.; Foret, F.; Bocek, P.; J. Chromatogr. 1985, 320, 159.

82. Foret, F.; Deml, M.; Kahle, V.; Bocek, P.; Electrophoresis 1986, 7, 430.

83. Huang, X.; Pang, T-K. J.; Gordon, M. J.; Zare, R. N.; Anal. Chem. 1987 59,2747

84. Huang, X.; Zare, R. N.; Sloss, S.; Ewing, A. G.; Anal. Chem. 1991, 63, 189.

85. Huang. X.; Zare, R. N.; Anal. Chem. 1991, 63, 2193.

86. Dasgupta, P. K.; Bao, L.; Anal. Chem. 1993, 65, 1003.

87. Avdalovic, N.; Pohl, C. A.; Rocklin, R. D.; Stillian, J. R.; Anal. Chem. 1993, 65,1470 .

88. Harrold, M.; Stillian, J.; Bao, L.; Rocklin, R.; Avdalovic, N.; J. Chromatogr., A 1995, 717, 371.

89. Dasgupta, P. K.; Kar, S.; Anal. Chim. Acta 1999, 394, 1

90. Dasgupta, P. K.; Kar, S.; Anal. Chem. 1995, 67, 3853.

91. Kar, S.; Dasgupta, P. K.; Liu, H.; Hwang, H.; Anal. Chem. 1994, 66, 2537.

92. Müller, D.; Jelínek, I.; Opekar, F.; Stulík, K.; Electroanalysis 1996, 8, 722

93. Zhao, H.; Dadoo, R.; Reay, R. J.; Kovacs, G. T. A.; Zare, R. N.; J. Chromatogr., A 1998, 813, 205.

94. Tuma, P.; Opekar, F.; Jelínek, I.; Stulík, K.; Electroanalysis 1999, 11, 1022

95. Vaireanu, D. I.; Fielden, P. R.; Brown, B. J. T.; Meas. Sci. Technol. 2000, $11,244$.

96. Haber, C.; Jones, W. R.; Soglia, J.; Surve, M. A.; McGlynn, M.; Caplan, A.; Reineck, J. R.; Krstanovic, C.; J. Capillary Electrophor. Microchip Technol. 1996, 3, 1 .

97. Jones, W. R.; Soglia, J.; McGlynn, M.; Haber, C.; Reineck, J.; Krstanovic, C.; Am. Lab. 1996, 28, 25.

98. Wanders, B. J.; van de Goor, T. A. A. M.; Everaerts, F. M.; J. Chromatogr. A 1993, 652, 291.

99. Govindaraju, K.; Ahmed, A.; Lloyd, D. K.; J. Chromatogr., A 1997, 768, 3.

100. Fu, S.; Lucy, C. A.; Anal. Chem. 1998, 70, 173.

101. Gebauer, P.; Caslavska, J.; Thormann, W.; Bocek, P.; J. Chromatogr., A 1997, 772, 63.

102. Schlegel, D.; Mattusch, J.; Wennrich, R.; Fresenius J. Anal. Chem. 1996 $354,535$.

103. Valsecchi, S.; Tartari, G.; Polesello, S.; J. Chromatogr., A 1997, 760, 326.

104. Kaniansky, D.; Zelenská, V.; Baluchová, D.; Electrophoresis 1996, 17, 1890.

105. Gebauer, P.; Deml, M.; Bocek, P.; Janák, J.; J. Chromatogr. 1983, 267, 455.

106. Rosso, T. E.; Bossle, P. C.; J. Chromatogr., A 1998, 824, 125.

107. Nassar, A-E. F.; Lucas, S. V.; Jones, W. R.; Hoffland, L. D.; Anal. Chem. 1998, 70, 1085 .

108. Hissner, F.; Mattusch, J.; Heinig, K.; J. Chromatogr., A 1999, 848, 503.

109. Klampfl, C. W.; J. Agric. Food Chem. 1999, 47, 987.

110. Klampfl, C. W.; Katzmayr, M. U.; J. Chromatogr., A 1998, 822, 117.

111. Klampfl, C. W.; Katzmayr, M. U.; Buchberger, W.; Electrophoresis 1998, 19,2459

112. Klampfl, C. W.; Katzmayr, M. U.; Buchberger, W.; Basener, N.; J. High Resol. Chromatogr. 1999, 22, 297.
113. Klampfl, C. W.; J. Capillary Electrophor. Microchip Technol. 1998, 5, 125.

114. Klampfl, C. W.; Katzmayr, M. U.; Buchberger, W.; Basener, N.; J. Chromatogr., A 1998, 804, 357.

115. Meissner, Th.; Eisenbeiss, F.; Jastorff, B.; J. Chromatogr., A 1998, 829, 351.

116. Govindaraju, K.; Cowley, E. A.; Eidelman, D. H.; Lloyd, D. K.; Anal. Chem. 1997, 69, 2793.

117. Williams, R. C.; Boucher, R. J.; J. Pharm. Biomed. Anal. 2000, 22, 115.

118. Stocking, C. J.; Slater, J. M.; Unwin, R.; Walter, S.; Folkerd, E.; Kidney Int. 1999, 56, 338 .

119. Gallagher, P. A.; Oertel, C. M.; Danielson, N. D.; J. Chromatogr., A 1998, 817,31 .

120. Gallagher, P. A.; Danielson, N. D.; J. Chromatogr., A 1997, 781, 533.

121. Hissner, F.; Mattusch, J.; Heinig, K.; Fresenius J. Anal. Chem. 1999, 365, 647.

122. Kaniansky, D.; Zelenský, I.; Hybenová, A.; Onuska, F. I.; Anal. Chem. 1994, 66, 4258.

123. Haber, C.; VanSaun, R. J.; Jones, W. R.; Anal. Chem. 1998, 70, 2261.

124. Katzmayr, M. U.; Klampfl, C. W.; Buchberger, W.; J. Chromatogr., A 1999, $850,355$.

125. Lucy, C. A.; Wu, Q.; J. Chromatogr. Sci. 1998, 36, 33.

126. Zemann, A. J.; Schnell, E.; Volgger, D.; Bonn, G. K.; Anal. Chem. 1998, $70,563$.

127. Fracassi da Silva, J. A.; Lago, C. L.; Anal. Chem. 1998, 70, 4339.

128. Mayrhofer, K.; Zemann, A. J.; Schnell, E.; Bonn, G. K.; Anal. Chem. 1999, $71,3828$.

129. Kaniansky, D.; Zelenská, V.; Masár, M.; Iványi, F.; Gazdíková, S.; J. Chromatogr., A 1999, 844, 349.

130. Masár, M.; Bodor, R.; Kaniansky, D.; J. Chromatogr., A 1999, 834, 179.

131. Mikus, P.; Kaniansky, D.; Sebesta, R.; Salisová, M.; Enantiomer 1999, 4, 279.

132. Fracassi da Silva, J. A.; Lago, C. L.; Electrophoresis 2000, 21, 1405.

133. Sloss, S.; Ewing, A. G.; Anal. Chem. 1993, 65, 577.

134. Chen, M.-C.; Huang, H.-J.; Anal. Chem. 1995, 67, 4010.

135. Matysik, F.-M.; Backofen, U.; Fresenius J. Anal. Chem. 1996, 356, 169.

136. Matysik, F.-M.; J. Chromatogr., A 1996, 742, 229.

137. Fu, C.; Wang, L.; Instrum. Sci. Technol. 1999, 27, 199.

138. Hua, L.; Tan, S. N.; Anal. Chim. Acta 2000, 403, 179.

139. Hua, L.; Tan, S. N.; Anal. Chem. 2000, 72, 4821.

140. Hua, L.; Tan, S. N.; Fresenius J. Anal. Chem. 2000, 367, 697.

141. Jin, W.; Dong, Q.; Yu, D.; Ye, X.; Li, W.; Electrophoresis 2000, 21, 1540

142. Ye, J.; Baldwin, R. P.; Anal. Chem. 1993, 65, 3525.

143. Holland, L. A.; Harmony, N. M.; Lunte, S. M.; Electroanalysis 1999, 11, 327.

144. Chen, D.-C.; Chang, S.-S.; Chen, C.-H.; Anal. Chem. 1999, 71, 3200

145. Zhong, M.; Lunte, S. M.; Anal. Chem. 1999, 71, 251.

146. Lin, B. L.; Colón, L. A.; Zare, R. N.; J. Chromatogr., A 1994, 680, 263.

147. Voegel, P. D.; Baldwin, R. P.; Electrophoresis 1998, 19, 2226.

148. Matysik, F.-M.; Björefors, F.; Nyholm, L.; Anal. Chim. Acta 1999, 385, 409.

149. Niwa, O.; Kurita, R.; Liu, Z.; Horiuchi, T.; Torimitsu, K.; Anal. Chem. 2000 $72,949$.

150. Liu, Z.; Niwa, O.; Kurita, R.; Horiuchi, T.; Anal. Chem. 2000, 72, 1315

151. Slater, J. M.; Watt, E. J.; Analyst 1994, 119, 2303.

152. Jin, W.; Chen, H.; J. Chromatogr., A 1997, 765, 307.

153. Jin, W.; Chen, H.; J. Electroanal. Chem. 1997, 425, 155.

154. Jin, W.; Jin, L.; Shi, G.; Ye, J.; Anal. Chim. Acta 1999, 382, 33.

155. Bai, X.; You, T.; Sun, H.; Yang, X.; Wang, E.; Electroanalysis 2000, 12 , 1379.

156. Chen, G.; Ye, J. N.; Cheng, J. S.; Chromatographia 2000, 52, 137.

157. Ye, J.; Baldwin, R. P.; Anal. Chem. 1994, 66, 2669.

158. Guo, Y.; Colón, L. A.; Dadoo, R.; Zare, R. N.; Electrophoresis 1995, 16, 493.

159. Swanek, F. D.; Anderson, B. B.; Ewing, A. G.; J. Microcolumn Sep. 1998, 10,185

160. Xu, D.-K.; Lin, H.; Chen, H.-Y.; Anal. Chim. Acta 1997, 349, 215.

161. Jin, W.; Weng, Q.; Wu, J.; Anal. Chim. Acta 1997, 342, 67.

162. Jin, W.; Dong, Q.; Yu, D.; Ye, X.; Electrophoresis 2000, 21, 1535.

163. Smith, A. R.; Kirchoff, J. R.; Hudson, R. A.; Tillekeratne, L. M. V.; Anal. Commun. 1999, 36, 371 .

164. Xu, D.-K.; Hua, L.; Chen, H.-Y.; Anal. Chim. Acta 1996, 335, 95.

165. Lin, H.; Xu, D.-K.; Chen, H.-Y.; J. Chromatogr., A 1997, 760, 227.

166. Weiss, D. J.; Lunte, C. E.; Electrophoresis 2000, 21, 2080.

167. Yang, W.-C.; Dai, Y.-Q.; Yu, A.-M.; Chen, H.-Y.; J. Chromatogr., A 2000, $867,261$.

168. You, T.; Liu, Z.; Yang, X.; Wang, E.; Talanta 1999, 49, 517.

169. Hong, J.; Baldwin, R. P.; J. Capillary Electrophor. Microchip Technol. 1997, 4, 65. 
170. Xu, D.-K.; Hua, L.; Li, Z.-M.; Chen, H.-Y.; J. Chromatogr., B 1997, 694, 461.

171. Jin, W.; Wang, Y.; Anal. Chim. Acta 1997, 343, 231.

172. O'Shea, T. J.; Telting-Diaz, M. W.; Lunte, S. M.; Lunte, C. E.; Smyth, M. R.; Electroanalysis 1992, 4, 463.

173. Wang, R.; Lu, X.; Wu, M.; Wang, E.; J. Chromatogr., B 1999, 721, 327.

174. You, T. Y.; Niu, L.; Gui, J. Y.; Dong, S. J.; Wang, E. K.; J. Pharm. Biomed. Anal. 1999, 19, 231.

175. You, T.; Yang, X.; Wang, E.; Talanta 2000, 51, 1213.

176. Jin, W.; Zhang, J.; J. Chromatogr., A 2000, 868, 101.

177. Jin, W.; Ye, X.; Yu, D.; Dong, Q.; J. Chromatogr., B 2000, 741, 155.

178. Chen, G.; Ding, X.; Cao, Z.; Ye, J.; Anal. Chim. Acta 2000, 408, 249.

179. Jin, W.; Ye, X.; Yu, D.; Dong, Q.; Anal. Chim. Acta 2000, 408, 257.

180. Hu, Q.; Zhang, L.; Zhou, T.; Fang, Y.; Anal. Chim. Acta 2000, 416, 15.

181. Chen, G.; Zhang, H.; Ye, J.; Anal. Chim. Acta 2000, 423, 69.

182. Jin. W.; Li, W.; Xu, Q.; Dong, Q.; Electrophoresis 2000, 21, 1409.

183. You, T.; Yang, X.; Wang, E.; Anal. Chim. Acta 1999, 401, 29.

184. Chen, G.; Ying, X.; Ye, J.; Analyst 2000, 125, 815.

185. Chen, G.; Zhang, H.; Ye, J.; Talanta 2000, 53, 471.

186. Hilmi, A.; Luong, J. H. T.; Nguyen, A.-L.; J. Chromatogr., A 1997, 761, 259.

187. Gaitonde, C. D.; Pathak, P. V.; J. Chromatogr. 1990, 514, 389.

188. Hilmi, A.; Luong, J. H. T.; Nguyen, A.-L.; Environ. Sci. Technol. 1997, $31,1794$.

189. Huang, X.; You, T.; Li, T.; Yang, X.; Wang, E.; Electroanalysis 1999, 11, 969.

190. Lai, E. P. C.; Zhang, W.; Trier, X.; Georgi, A.; Kowalski, S.; Kennedy, S.; MdMuslim, T.; Dabek-Zlotorzynska, E.; Anal. Chim. Acta, 1998, 364, 63.

191. Hilmi, A.; Luong, J. H. T.; Nguyen, A.-L.; Anal. Chem. 1999, 71, 873.

192. Hilmi, A.; Luong, J. H. T.; Electrophoresis 2000, 21, 1395.

193. Wallenborg, S. R.; Dorholt, S. M.; Faibushevich, A.; Lunte, C. E.; Electroanalysis 1999, 11, 362 .

194. Tenberken, B.; Ebert, P.; Hartmann, M.; Kibler, M.; Mainka, A.; Prokop, T.; Röder, A.; Bächmann, K.; J. Chromatogr., A 1996, 745, 209.

195. Rüttinger, H.-H.; Radschuweit, A.; J. Chromatogr., A 2000, 868, 127.

196. Lu, W.; Cassidy, R. M.; Baransky, A. S.; J. Chromatogr. 1993, 640, 433.

197. Colón, L. A.; Dadoo, R.; Zare, R. N.; Anal. Chem. 1993, 65, 476.

198. Ye, J.; Baldwin, R. P.; J. Chromatogr., A 1994, 687, 141.

199. Zhou, W.; Baldwin, R. P.; Electrophoresis 1996, 17, 319.

200. Fermier, A. M.; Colón, L. A.; J. High Resolut. Chromatogr. 1996, 19, 613.

201. Chen, M.-C.; Huang, H.-J.; Anal. Chim. Acta 1997, 341, 83.

202. Salimi-Moosavi, H.; Cassidy, R. M.; Anal. Chem. 1995, 67, 1067.

203. Matysik, F.-M.; J. Chromatogr., A 1998, 802, 349.

204. Matysik, F.-M.; Electroanalysis 1999, 11, 1017.

205. Matysik, F.-M.; J. Chromatogr., A 1999, 853, 27

206. Luong, J. H. T.; Hilmi, A.; Nguyen, A.-L.; J. Chromatogr., A 1999, 864, 323.

207. Matysik, F.-M.; Anal. Chem. 2000, 72, 2581.

208. Backofen, U.; Matysik, F.-M.; Hoffmann, W.; Lunte, C. E.; Fresenius J. Anal. Chem. 2000, 367, 359.

209. Hadwiger, M. E.; Torchia, S. R.; Park, S.; Biggin, M. E.; Lunte, C. E.; J. Chromatogr., B 1996, 681, 241.

210. Fang, X.; Gong, F.; Fang, Y.; Anal. Chem. 1998, 70, 4030.

211. Jin, W.; Wang, Y.; J. Chromatogr., A 1997, 769, 307.

212. Jin, W.; Li, W.; Xu, Q.; Electrophoresis 2000, 21, 774.

213. Zhou, J.; O’Shea, T. J.; Lunte, S. M.; J. Chromatogr., A 1994, 680, 271.

214. Fu, C.; Wang, L.; Fang, Y.; Anal. Chim. Acta 1999, 391, 29.

215. O'Shea, T. J.; Lunte, S. M.; Anal. Chem. 1994, 66, 307.

216. Fu, C.; Wang, L.; Fang, Y.; Talanta 1999, 50, 953.

217. Chen, H.-Y.; Yu, A.-M.; Xu, D.-K.; Fresenius J. Anal. Chem. 1997, 359, 542.

218. Yang, W.-C.; Yu, A.-M.; Dai, Y.-Q.; Chen, H.-Y.; Anal. Lett. 2000, 33, 3343.

219. Niu, L.; You, T.; Gui, J. Y.; Wang, E.; Dong, S.; J. Electroanal. Chem. 1998, 448,79

220. O'Shea, T. J.; Lunte, S. M.; LaCourse, W. R.; Anal. Chem. 1993, 65, 948.

221. Lu, W.; Cassidy, R. M.; Anal. Chem. 1993, 65, 2878.

222. Roberts, R. E.; Johnson, D. C.; Electroanalysis 1995, 7, 1015.

223. Voegel, P. D.; Baldwin, R. P.; Am. Lab. 1996, 28, 39.

224. Zhong, M.; Lunte, S. M.; Anal. Chem. 1996, 68, 2488.

225. Weber, P. L.; Lunte, S. M.; Electrophoresis 1996, 17, 302.

226. LaCourse, W. R.; Owens, G. S.; Electrophoresis 1996, 17, 310.

227. Zhong, M.; Lunte, S. M.; Anal. Commun. 1998, 35, 209.
228. Lu, W.; Cassidy, R. M.; Anal. Chem. 1993, 65, 1649

229. Wen, J.; Cassidy, R. M.; Anal. Chem. 1996, 68, 1047.

230. Voegel, P. D.; Baldwin, R. P.; Electroanalysis 1997, 9, 1145.

231. Owens, G. S.; LaCourse, W. R.; J. Chromatogr., B 1997, 695, 15.

232. Haber, C.; Silvestri, I.; Röösli, S.; Simon, W.; Chimia 1991, 45, 117.

233. Nann, A.; Silvestri, I.; Simon, W.; Anal. Chem. 1993, 65, 1662.

234. Nann, A.; Simon, W.; J. Chromatogr. 1993, 633, 207.

235. Hauser, P. C.; Renner, N. D.; Hong, A. P. C.; Anal. Chim. Acta 1994, 295 , 181

236. Nann, A.; Pretsch, E.; J. Chromatogr., A 1994, 676, 437.

237. Hauser, P. C.; Hong, A. P. C.; Renner, N. D.; J. Capillary Electrophor. Microchip Technol. 1995, 2, 209.

238. Spichiger, U. E.; Fakler, A.; Electrochim. Acta 1997, 42, 3137.

239. De Backer, B. L.; Nagels, L. J.; Anal. Chem. 1996, 68, 4441.

240. Kappes, T.; Schnierle, P.; Hauser, P. C.; Anal. Chim. Acta 1997, 350, 141.

241. Schnierle, P.; Kappes, T.; Hauser, P. C.; Anal. Chem. 1998, 70, 3585.

242. Kappes, T.; Hauser, P. C.; Anal. Commun. 1998, 35, 325.

243. Poels, I.; Nagels, L. J.; Anal. Chim. Acta 1999, 385, 417.

244. Kappes, T.; Schnierle, P.; Hauser, P. C.; Anal. Chim. Acta 1999, 393, 77.

245. Poels, I.; Nagels, L. J.; Anal. Chim. Acta 1999, 401, 21.

246. Kappes, T.; Schnierle, P.; Hauser, P. C.; Electrophoresis 2000, 21, 1390.

247. Kappes, T.; Hauser, P. C.; Anal. Chim. Acta 1997, 354, 129.

248. Buchberger, W.; Aichhorn, D.; Niessner, G.; Haddad, P. R.; Bogan, D.; Monatsh. Chem. 1998, 129, 811 .

249. Macka, M.; Gerhardt, G.; Andersson, P.; Bogan, D.; Cassidy, R. M.; Haddad, P. R.; Electrophoresis 1999, 20, 2539.

250. Zakaria, P.; Macka, M.; Gerhardt, G.; Haddad, P. R.; Analyst 2000, 125, 1519.

251. Ferris, S. S.; Lou, G.; Ewing, A. G.; J. Microcolumn Sep. 1994, 6, 263.

252. Swanek, F. D.; Chen, G.; Ewing, A. G.; Anal. Chem. 1996, 68, 3912-3916.

253. Park, S.; McGrath, M. J.; Smyth, M. R.; Diamond, D.; Lunte, C. E.; Anal. Chem. 1997, 69, 2994.

254. Gerhardt, G. C.; Cassidy, R. M.; Baranski, A. S.; Anal. Chem. 1998, 70, 2167.

255. Gerhardt, G. C.; Cassidy, R. M.; Baranski, A. S.; Anal. Chem. 2000, 72, 908

256. Magnuszewska, J.; Krogulec, T.; Baranski, A. S.; Chem. Anal. 2000, 45, 189.

257. Wen, J.; Baranski, A. S.; Cassidy, R. M.; Anal. Chem. 1998, 70, 2504.

258. Wen, J.; Cassidy, R. M.; Baranski, A. S.; J. Chromatogr., A 1998, 811, 181.

259. Zhou, J.; Gerhardt, G. C.; Baranski, A.; Cassidy, R.; J. Chromatogr., A 1999, 839, 193

260. Zhou, J.; Chen, Y.; Cassidy, R.; Electrophoresis 2000, 21, 1349.

261. Gavin, P. F.; Ewing, A. G.; J. Am. Chem. Soc. 1996, 118, 8932

262. Gavin, P. F.; Ewing, A. G.; Anal. Chem. 1997, 69, 3838.

263. Gavin, P. F.; Ewing, A. G.; J. Microcolumn Sep. 1998, 10, 357.

264. Wooley, A. T.; Lao, K.; Glazer, A. N.; Mathies, R. A.; Anal. Chem. 1998, 70,684

265. Wang, J.; Tian, B.; Sahlin, E.; Anal. Chem. 1999, 71, 3901.

266. Hilmi, A.; Luong, J. H. T.; Anal. Chem. 2000, 72, 4677.

267. Wang, J.; Tian, B.; Sahlin, E.; Anal. Chem. 1999, 71, 5436

268. Wang, J.; Chatrathi, M. P., Tian, B.; Polsky, R.; Anal. Chem. 2000, 72, 2514.

269. Wang, J.; Chatrathi, M. P., Tian, B.; Anal. Chem. 2000, 72, 5774.

270. Wang, J.; Chatrathi, M. P.; Tian, B.; Polsky, R.; Electroanalysis 2000, 12, 691

271. Wang, J.; Chatrathi, M. P.; Tian, B.; Anal. Chim. Acta 2000, 416, 9.

272. Rossier, J. S.; Ferrigno, R.; Girault, H. H.; J. Electroanal. Chem. 2000, 492,15

273. Martin, R. S.; Gawron, A. J.; Lunte, S. M.; Henry, C. S.; Anal. Chem. 2000, $72,3196$.

274. Henry, C. S.; Zhong, M.; Lunte, S. M.; Kim, M.; Bau, H.; Santiago, J. J.; Anal. Commun. 1999, 36, 305.

275. Hilmi, A.; Luong, J. H. T.; Environ. Sci. Technol. 2000, 34, 3046

276. Baba, Y.; Electrochemistry 2000, 68, 197.

277. Wang, J.; Polsky, R.; Tian, B.; Chatrathi, M. P.; Anal. Chem. 2000, 72, 5285

278. Huang, X.; Gordon, M. J.; Zare, R. N.; J. Chromatogr. 1988, 425, 385

279. Huang, X.; Luckey, J. A.; Gordon, M. J.; Zare, R. N.; Anal. Chem. 1989, $61,766$.

280. Wiliams, R. C.; Boucher, R.; Brown, J.; Scull, J. R.; Walker, J.; Paolini, D.; J. Pharm. Biomed. Anal. 1997, 16, 469. 